\title{
O USO DO TEXTO LITERÁRIO NO ENSINO BILÍNGUE E MULTIMODAL DE PORTUGUÊS PARA CRIANÇAS SURDAS - REFLEXÕES SOBRE A PRODUÇÃO DE UM MATERIAL DIDÁTICO
}

\author{
THE USE OF THE LITERARY TEXT IN THE BILINGUAL AND \\ MULTIMODAL TEACHING OF PORTUGUESE TO DEAF CHILDREN - \\ REFLECTIONS ON THE PRODUCTION OF A TEACHING MATERIAL
}

\author{
Dayse Garcia Miranda ${ }^{1}$ \\ Renato Caixeta da Silva ${ }^{2}$ \\ Luciana Aparecida Guimarães de Freitas ${ }^{3}$
}

\section{RESUMO}

Partindo da necessidade dos alunos surdos aprenderem duas línguas distintas, simultaneamente, Libras e Língua Portuguesa, neste artigo propõe-se mostrar como um texto literário em português pode ser um recurso didático de ensino para o aprendizado de língua portuguesa como L2 e ao mesmo tempo ensino de Libras. Objetiva-se reflexões a respeito de ensino de línguas, sobre a multimodalidade, e quanto à elaboração de material didático dentro da perspectiva da surdez, como também mostrar como as imagens e diferentes línguas podem contribuir para que alunos surdos se tornem usuários dessas duas línguas. Aspectos do material proposto são discutidas em conjunto com partes do material, do mesmo modo a avaliação sobre a implementação em dois diferentes contextos. Desta forma, aponta-se a riqueza do material e a relevância da orientação de ensino para implementação do material. Por fim, argumenta-se em favor de uma pedagogia de segunda língua para surdos que seja bilíngue e multimodal.

\section{Palavras-Chave}

Libras. PL2. Multimodalidade.

\section{Abstract}

Starting from the need of deaf students to learn two distinct languages simultaneously, Libras and Portuguese Language, in this, it is proposed to show how a literary text in Portuguese can be a teaching resource for learning Portuguese language as $L 2$ and at the same time teaching Libras. It aims to reflect on language teaching, on multimodality, and on the development of teaching material within the perspectives of deafness, as well as show how images and the different languages, can contribute to deaf students become users of these two languages. Aspects of the proposed material are discussed together with parts of the material, in the same way the evaluation on the implementation in two different contexts. In this way, it is pointed out the richness of the material and the relevance of the teaching orientation for the implementation of the material. At last, it is argued in favor of bilingual and multimodal L2 pedagogy for deaf students.

\section{KeYwORDS}

Libras. PL2. Multimodality.

\footnotetext{
1 Doutora em Estudos de Linguagens pelo Centro Federal de Educação Tecnológica de Minas Gerais, professora da Universidade Federal de Ouro Preto.

2 Doutor em Letras pela Pontifícia Universidade Católica do Rio de Janeiro, professor do Centro Federal de Educação Tecnológica de Minas Gerais.

3 Doutoranda em Estudos de Linguagem pelo Centro Federal de Educação Tecnológica de Minas Gerais.
} 


\section{INTRODUÇÃo}

Estudos sobre a aquisição e o uso de duas ou mais línguas revelam que a mente humana é capaz de lidar com situação de contato entre os códigos semióticos, como também tem habilidade para buscar recursos linguísticos de cada língua dentro dos receptivos espaços de usos. À medida que se avança no processo de aquisição das línguas, se estabelecem novas formas de organização no uso das línguas circulantes.

Nesse sentido, torna-se possível supor que a diferença quanto à modalidade das línguas envolvidas, em especifico, Língua de Sinais (LS) e Língua Portuguesa (LP) escrita, modo verbal escrito, seja o princípio que oriente suas políticas de uso e domínio, no contexto escolar. Para isso, é importante focar as discussões a respeito da aquisição bilíngue da criança surda: uma aquisição que envolve dois diferentes modos operacionais de língua - o verbal escrito (língua portuguesa) e o visuoespacial (LS). Essa diferenciação de modos pode configurar processos específicos de aquisição linguística e de como o uso dos recursos linguísticos ocorrem no decorrer da aprendizagem das línguas.

A LS, primeira língua (L1), para as crianças surdas, pode ter papel fundamental na aquisição da segunda língua (L2), no caso o português escrito. A proficiência na primeira língua contribui para o desenvolvimento da segunda, pois o conhecimento linguístico e conceitual da L1 é transferido para a L2. Esse embasamento se sustenta pelo princípio da Interdependência Linguística, de Cummins (1994, 1996 apud CARVALHO, 2013), a saber, na medida em que a instrução em L1 é eficaz na promoção de sua proficiência, a transferência dessa proficiência para a L2 ocorrerá desde que haja exposição adequada à L2 e motivação adequada para aprendê-la. Dessa maneira, afirma-se que a L1 é um recurso importante para o desenvolvimento da competência da L2. L1 é a referência, e em se tratando de surdos, muitas vezes (ou na maioria), crianças em idade escolar são inseridas no meio educacional formal sem domínio da língua de sinais, sua L1 que seria a referência para o ensino de L2, o português na modalidade escrita.

Quanto à surdez, existe um consenso entre os pesquisadores com relação ao status da L2: a língua escrita pode ser adquirida diretamente por crianças surdas com formação bilíngue como uma segunda língua (PLAZA-PUST, 2012; MAYBERRY, 2007; ANN, 2004, PEREIRA, 2009). No entanto, há pouca constatação sobre a criança surda poder compensar a falta de acesso à língua oral tomando outros caminhos na aprendizagem de escrita de outra língua e, assim, ter êxito na L2. Segundo Plaza-Pust (2012), pesquisadores se dividem quando discutem a aquisição da escrita pela criança surda. Alguns consideram importante ponderar quanto ao impacto da perda auditiva e seus efeitos no desenvolvimento da escrita de crianças surdas, principalmente em relação ao papel da consciência fonológica no desenvolvimento da alfabetização. Outros enfatizam que é preciso olhar para a língua escrita por si só.

Günther (2003), por exemplo, mantém que, embora a língua escrita esteja relacionada à língua oral, ela apresenta um sistema semiótico autônomo. Os alunos devem "decifrar o código" ao longo do texto proposto, para a especifica situação de aquisição, ou seja, eles têm que identificar as unidades relevantes de cada nível, as regras que governam a sua combinação, bem como a inter-relação dos diferentes níveis linguísticos de análise. 
O conhecimento inato e o ambiente linguístico contribuem para este processo (PLAZA-PUST 2012, p. 964. Tradução nossa). ${ }^{4}$

Para alguns profissionais, é certa a crença de que a escrita representa a língua falada, e postula-se que o leitor deve ser capaz de falar a língua que está representada na escrita para, assim, compreendê-la. Partindo desse princípio, a criança surda brasileira não fala o português, e, por sua vez, não seria capaz de ler e escrever nesta língua como sua segunda língua. No entanto, essa ideia está em desacordo com os resultados de diferentes investigações, que revelam que a L1 das crianças surdas (no caso, a LS) orienta o aprendizado da L2 escrita, pois ambas apresentam elementos visuais na sua estrutura. Nota-se uma correspondência entre habilidade gramatical em LS e capacidade de leitura em L2, o que é um exemplo de bilinguismo bimodal.

Pesquisadores como Plaza-Pust (2012) e Mayberry (2007) afirmam que a restrita quantidade de insumo de leituras ofertada à criança surda é um dos fatores que engessam o desenvolvimento da língua escrita (L2), por essas crianças. A diferença entre os grupos de alunos no desenvolvimento está na diversificação na quantidade de entrada (acesso/contato) disponível: enquanto as crianças ouvintes são continuamente expostas à língua portuguesa como L1, as crianças surdas têm pouco acesso e contato com ela, que para eles é L2 na modalidade escrita, e também pouco ou quase nenhum contato com a LS, sua L1. Assim, a variação nas produções dos alunos é um indicador dos processos dinâmicos de aprendizagem que moldam a organização da língua. De forma complementar, onde a língua escrita serve como L2, o papel da LS como L1 no seu desenvolvimento é importante para uma compreensão apropriada de como as crianças surdas podem lucrar com seus recursos linguísticos no curso do desenvolvimento bilíngue (PLAZA-PUST, 2012, p. 965).

A partir disso, neste artigo procuramos assumir que apresentar diferentes gêneros discursivos é dar à criança surda a oportunidade de lidar com diversos tipos linguísticos da segunda língua. Essa diversidade fundamenta-se nas práticas comunicativas entre os participantes desse ambiente de ensino. Nesse contexto, pode-se pressupor que, por um lado, as diferenças de modalidade (em si) não sirvam como um indicador de qual modo predomina. Pesquisadores (PADDEN; RAMSEY, 2008 apud PLAZA-PUST, 2012) têm observado a importância de pistas estruturais e pragmáticas no fornecimento de informações sobre as diferenças entre as línguas. Em particular, papéis didáticos distintos para as diferentes línguas usadas em sala de aula parecem ser fundamentais para o sucesso do desenvolvimento bilíngue de alunos surdos.

Assim, entendemos que o aluno surdo deve ter a consciência das semelhanças e das diferenças de cada língua e cada código semiótico. Isso o ajudará a explorar habilmente os recursos linguísticos de significação em favor do domínio do conteúdo. Professores (surdos e ouvintes) e alunos utilizam criativamente seus recursos linguísticos em situações dinâmicas de comunicação, e, assim, as crianças aprendem a refletir sobre a linguagem, sua estrutura e seu uso (PADDEN; RAMSEY, 2008 apud PLAZA-PUST, 2012, p. 969).

A aquisição de linguagem é um processo complexo para crianças surdas. E esse processo não envolve apenas línguas diferentes como seria o português e o inglês, ou português e espanhol, em

4 No original em inglês: "Gunther (2003), for example, maintains that although written language is related to spoken language, it is an autonomous semiotic system. Learners must 'crack the code' along the lines proposed for other acquisition situations, that is, they have to identify the relevant units of each linguistic level, the rules that govern their combination, as well as the inter-relation of the different linguistic levels of analysis. Both innate knowledge and linguistic environment are assumed to contribute to this process". 
que ambas as línguas são faladas e escritas - mesmo código semiótico, o verbal. No caso da educação linguística de crianças surdas, modos diferentes estão envolvidos, além dos códigos (L1 e L2) serem diferentes. A LS a ser aprendida também é visuoespacial, ${ }^{5}$ enquanto o português como L2 é verbal escrito. Por isso pensamos ser importante que ações educacionais envolvendo educação linguística de surdos deve considerar a multimodalidade ali presente e envolvida. A multimodalidade é tema da próxima seção.

\section{Multimodalidade como base para o ensino de L2 PARA SURdos.}

O conceito de multimodalidade, de acordo Hemais (2015), é a combinação de diferentes modos de significação e de comunicação no uso da linguagem. Kress (2010) afirma que essa é a condição padrão de comunicação humana, pois desde sempre o ser humano utiliza, em seus momentos de criação e comunicação de mensagens, diversos códigos semióticos, como imagens, língua oral, língua escrita, gestos, a organização espacial, cores, música, e outros. Assumimos isso, e reiteramos as ideias dos autores mencionados de que os modos semióticos não funcionam separadamente numa situação de comunicação humana.

Em se tratando de ensino e aprendizagem, é a partir da noção de multimodalidade que se considera a ideia comumente divulgada de multiletramentos, principalmente tendo em mente os avanços tecnológicos digitais mais recentes. Com essa tecnologia, o acesso aos recursos de significação ficou mais fácil e democrático, fazendo parte do cotidiano de muitas crianças e adolescentes em idade escolar. Com isso, é preciso educar crianças e jovens para uso da linguagem a partir das possibilidades presentes no cotidiano de uso das diferentes linguagens, ou modos de significação e comunicação. Mas, não se pode esquecer que, apesar de tradicionalmente modelos instrucionais e de compreensão textual serem guiados majoritariamente por aspectos cognitivos (SERAFINI, 2011), a multimodalidade sempre esteve presente nos materiais didáticos usados nas escolas e nas salas de aula, pois a língua escrita sempre divide espaço, em geral, com imagens, a oralidade do professor, as cores, por exemplo. Porém, este fato nem sempre parece ser enfatizado pelo professor ou pelos autores dos livros didáticos e outros materiais em manuais endereçados ao professor, o que defendemos que aconteça na educação linguística de surdos, de maneira mais consciente e frequente.

Partindo disso, defendemos que a consideração constante da multimodalidade deve ser levada em conta no ensino de língua portuguesa escrita para surdos, considerando a LS como L1 e a Língua Portuguesa como L2. Em se tratando de prática de ensino de português escrito e de outras línguas para usuários de Libras pode-se proporcionar ensino de língua portuguesa tendo em vista as habilidades de leitura e escrita, considerando os modos envolvidos (LS- visual e espacial; português - código verbal escrito; e imagens - visual), O uso de imagens parece-nos um recurso valioso, pois servem para mostrar, muitas vezes, os conceitos (significados) a que significantes (palavras ou expressões escritas, por exemplo) podem se referir, e ajudam na assimilação de formas linguísticas a serem reconhecidas nos momentos de leitura.

É preciso pensar, nos momentos de ensino, na independência dos modos embora convivam no mesmo lugar. Como dito, sempre estão presentes diferentes modos em sala de aula e nos processos de ensinar e de aprender, e com o surdo não é diferente. Mas talvez nos contextos de

5 Canal de percepção e transmissão da língua de sinais. O uso da visão para a percepção e o uso do espaço para a transmissão. 
educação linguística a esses alunos, a multimodalidade fique mais evidente, pois ao invés de apelar para o uso da língua oral e da metalinguística em explicações sobre léxico ou regras gramaticais, ou ao invés de se apelar para a oralidade em momentos de alfabetização - apropriação do código escrito, o uso consciente das imagens nesses momentos pode ser mais eficaz. Assim, acreditamos não apenas num ensino bilíngue para surdos, envolvendo LS e língua portuguesa, mas também em educação linguística multimodal para surdos, envolvendo sinais, imagens e o código verbal escrito.

A convivência do português escrito com a LS em si já implica em modalidades diferentes, (o que já são) ainda que haja também a presença de imagens. Entretanto, a convivência das duas línguas (português e LS) não pode ser entendida como tradução do texto escrito para Libras em todo momento, ainda que em imagens em movimento (vídeos). Essa tradução como método sistematizado e único em aulas de português escrito para surdos pode ser prejudicial se vier a ser o principal recurso usado para conversar e entender enunciados, por exemplo, e assim não se promove de fato a leitura em português, ou não se escreve em português, substituindo essa língua a ser aprendida pela LS. Em outras palavras, pode-se promover o entendimento do conteúdo expresso em português escrito por meio da LS numa tradução, mas não se aprende a usar, de fato, a Língua Portuguesa nos momentos de leitura e escrita, o que seria apropriar-se dela como usuário.

Usar a L2 nesses momentos é essencial para se promover empoderamento do surdo numa sociedade brasileira em que a Língua Portuguesa é hegemônica. Isso, acreditamos, pode proporcionar o caráter agentivo do aluno surdo como emissor e receptor de mensagens em diferentes códigos (no caso o português escrito como L2). Assim, o próprio aluno, por meio da língua escrita que está aprendendo, pode ser capaz de representar/construir as suas experiências no mundo, pode engajar-se no discurso e assim estabelecer relações com outros usuários de português, e ainda pode compor e organizar mensagens escritas para agir no mundo como surdo usuário de LS e como usuário de português escrito. Seria esse o motivo de se aprender a L2 e ter consciência sobre o que fazer com ela. Isso é ter em mente, como professor e aluno, que há uma transformação inerente ao engajamento nos processos de ensinar e de aprender. Em suma, considerar a especificidade de ensino de português para surdos é fazê-los engajarem-se no processo de uso da língua aprendida.

Acreditamos que o apelo ao visual seja revelador da visão de modo e de amplitude dos processos de significação e de comunicação (KRESS, 2010), e com isso, o planejamento e a produção de materiais e técnicas de ensino de português como L2 a surdos pode e deve partir de apelos visuais considerando não somente imagens de vídeo de tradução de português para LS, como também, e em grande quantidade e frequência, imagens estáticas ou em movimento e língua portuguesa. Sobre isso, com base em Freitas (2018) trazemos uma experiência e reflexões atinentes.

\section{CONSTRUINDO MATERIAL DIDÁTICO PARA O ENSINO DE LP}

Ao pensar sobre o ensino de Língua Portuguesa (L2) para alunos surdos nos anos iniciais, não se pode deixar de conceituar: alfabetização e letramento. Soares (2003) esclarece que essas palavras foram usadas ao longo dos anos com diferentes objetivos. Segundo a autora já estamos familiarizados com a palavra "alfabetização" e "letramento" é ainda um assunto novo nas práticas educacionais. Soares define que alfabetização é a ação de alfabetizar, de tornar 'alfabeto' (SOARES, 2003, p. 30-31). Quanto a letramento, Soares ainda diz: 
é o desenvolvimento das habilidades que possibilitam ler e escrever de forma adequada e eficiente, nas diversas situações pessoais, sociais e escolares em que precisamos ou queremos ler ou escrever diferentes gêneros e tipos de textos, em diferentes suportes, para diferentes objetivos, em interação com diferentes interlocutores, para diferentes funções (SOARES, 2015, s/p). ${ }^{6}$

Soares acredita que alfabetização e letramento são processos indissociáveis no ensino e aprendizagem das primeiras letras para o aluno que não se deve dissociar essas duas concepções chamando a atenção enfatizando as práticas sociais, e conclui que "letramento é o estado ou condição de quem se envolve nas numerosas e variadas práticas sociais de leitura e escrita" (SOARES, 2009, p. 44).

Com relação aos alunos surdos, é preciso considerar o que outros autores pensam sobre o assunto. De acordo com Fernandes (2006), os alunos surdos passarão de uma língua não-alfabética (a LS) para uma língua alfabética (a LP como L2). A autora considera a Língua Portuguesa com diferente estruturação em relação à LS, o que leva os alunos surdos a terem dificuldades no processo de aprendizagem da leitura e da escrita em LP. Sánchez (2002, p.12), por sua vez, questiona: "como alguém que não ouve e que, portanto, não pode discriminar os diferentes traços definitivos e talvez, nem sequer conceber os sons da fala, poderia correlacionar os sons às letras e vice-versa?” Os questionamentos e apontamentos de Fernandes (2006) e Sánchez (2002) quanto à maneira tradicional de alfabetização são levados em conta na experiência de produção de material didático apresentada neste artigo, fruto do trabalho de pesquisa de uma das autoras.

A elaboração do material didático foi motivada a partir, também, de alguns questionamentos feitos por profissionais da área da surdez e vivências particulares de profissionais na educação dos surdos, realidade vivenciada pelas autoras deste artigo. As escolas das redes estadual e municipal de Belo Horizonte recebem uma coleção de livros didáticos aprovados pelo Programa Nacional do Livro Didático, as Coleções Pitanguá e a Portas Abertas, que contam com CDs interativos e acessíveis em Libras. No entanto, a maioria dos professores (ou, arriscando, sua totalidade) não faz uso desse material na sala de aula pelo fato de boa parte dos alunos surdos não terem desenvolvidas a leitura e a escrita da LP de modo satisfatório que possa permitir o acompanhamento dos conteúdos no livro de diferentes disciplinas. Ainda, a maioria dos professores desconhece o material ou uma metodologia de trabalho com o livro didático adaptado aos surdos, tanto em situação de uma sala de aula apenas com alunos surdos ou numa sala mista de surdos e ouvintes.

Diante da situação acima descrita e das percepções dos materiais disponíveis para ensino de português para alunos surdos nos anos iniciais, verificamos que os materiais disponíveis são adaptações de materiais produzidos para o ensino de português para ouvintes, com comandos e textos traduzidos para Libras, tradução esta disponibilizada em DVD para uso do aluno em sala de aula. Isso exige uso de computador, e não se tem o cuidado de se ter atividades que não envolvam percepção auditiva (como atividades em que se trabalham diferenças dos sons em ca, ce, ci co, cu, o que não faria sentido ao surdo). Por isso, foi proposto o material aqui apresentado com o olhar voltado para as especificidades do aluno surdo, quanto à experiência visual (QUADROS, 2004) e seu entendimento em relação à leitura e à escrita de uma segunda língua, no caso o português na modalidade escrita.

6 Disponível em: http://bit.ly/2QVMuiN. Acesso em 15/02/2018. 
A produção do material didático aqui apresentado segue as ideias apresentadas por Leffa (2007), que mostram como a produção de materiais de ensino é uma sequência de atividades com o objetivo de criar um instrumento de aprendizagem a partir de algumas abordagens: (i) abordagem funcional, a ênfase está no objetivo para qual se usa a língua, mais na função do que na noção; (ii) abordagem baseada na tarefa, caracteriza-se por subordinar a aprendizagem da língua à execução de uma determinada tarefa e por fim (iii) abordagem baseada no conteúdo, a ênfase no conteúdo, usando a língua que o aluno precisa aprender (LEFFA, 2007, p. 25-26).

No material apresentado, há priorização do aspecto funcional da linguagem e de seu ensino, enfatizando-se a língua em uso, o ensino em contexto, sendo que as atividades estão contextualizadas de acordo com a história principal. São propostas atividades que lidam com a interpretação, a produção textual, a escrita de palavras e as relações com o contexto de cada aluno. Ademais, a partir da história principal, outros gêneros do discurso são trabalhados com os alunos, como a manchete de jornal e a receita de bolo.

Leffa sugere que duas ou mais abordagens sejam integradas na construção do material didático, de acordo com os objetivos da aprendizagem, e ainda ressalta que "a preocupação está em definir de maneira mais clara possível o que exatamente o aluno precisa aprender para atingir os objetivos definidos anteriormente" (LEFFA, 2007, p. 27). Isso foi levado em conta na produção do material apresentado. Atividades de compreensão de itens específicos usados no texto, reconhecimento e escrita de palavras específicas, produção de desenhos, leitura e reorganização de frases e textos mais extensos, além de jogos como caça palavras e escrita enigmática foram algumas das atividades que mostravam tanto o conteúdo trabalhado como o caráter funcional das linguagens envolvidas e do ensino.

$\mathrm{Na}$ definição de atividades e recursos, é importante e necessário saber relacionar a teoria com a prática para promover o ensino de uma língua. Leffa (2007) revela que o ensino de uma língua considera quatro grandes áreas: fala, escuta, leitura e escrita. Mas, ao preparar um material didático para alunos surdos, um dos cuidados foi em oferecer a este público alvo, um conteúdo através de atividades e recursos que favorecessem a visão, a leitura e a escrita com a mediação da Libras (LS), por valorizar outra via de aprendizagem - a visoespacial, pois, ainda temos, nas escolas regulares e de ensino especial, a influência da consciência fonológica, ou seja, a Língua Oral está presente no fazer pedagógico na sala de aula em que está o surdo.

Quanto ao ordenamento das atividades, Leffa considera dois critérios básicos: facilidade e necessidade. Inicia-se pelo mais fácil e, aos poucos, as atividades vão gradativamente para o mais difícil e para o que for mais útil para o aluno, com retorno mais rápido. Idealiza-se e defende-se que os dois critérios sejam utilizados em conjunto. $\mathrm{O}$ autor também cita os nove eventos instrucionais de Gagné (apud LEFFA, 2007, p. 32) como possíveis norteadores da gradação e da sequenciação de atividades: garantir atenção, informar os objetivos, acionar o conhecimento prévio, apresentar o conteúdo, facilitar a aprendizagem, solicitar desempenho, fornecer feedback, avaliar o desempenho e ajudar na retenção e transferência.

O autor nos diz ainda sobre a importância da motivação para a realização das atividades e para a aprendizagem dos conteúdos. Segundo Leffa (2007 p. 33), existem quatro estratégias básicas, de acordo com o modelo ARCS, desenvolvido por Jonh Keller, na Universidade do Estado da 
Flórida: (i) Atenção, para despertar e manter o interesse; (ii) Relevância, para mostrar a utilidade de uma tarefa; (iii) Confiança, para desenvolver uma expectativa de sucesso; (iv) e Satisfação, que mostre reconhecimento pelo esforço do aluno. Todas as estratégias estão intimamente ligadas à postura do professor frente aos seus alunos e à importância que o profissional da educação dá ao seu ensino e à aprendizagem do corpo discente.

Partindo então da necessidade dos alunos surdos aprenderem duas línguas distintas, simultaneamente, e do fato de chegarem à escola sem aquisição ou com aquisição tardia da Libras e da LP, o objetivo do material proposto é apresentar a Libras e a LP de modo que os alunos se tornem usuários dessas duas línguas - sinalizando em Libras e realizando leitura e produção textual em LP de maneira contextualizada e com entendimento sobre a função social do conteúdo e do gênero em questão.

As etapas da produção do material foram construídas a partir da leitura de textos de Soares (2009), Leffa (2007) e Silva (2016) e organizadas de acordo com o entendimento do que é o ensino de leitura e escrita para alunos surdos, que possuem outra língua de instrução mas que, a maioria das vezes, tanto a Libras quanto a LP escrita são aprendidas no espaço escolar.

O material didático é composto por 56 atividades - a partir de um texto literário intitulado A verdadeira história dos três porquinhos, do autor Jon Scieszka. O texto foi dividido por partes, e pistas visuais (imagens) sobre trechos da história permitiram ao aluno a compreensão do conteúdo escrito, considerando o letramento visual (LEBEDEFF, 2010; TAVEIRA, ROSADO, 2013).

A escolha pelo texto literário deve-se por ser ele um uso significativo da língua e por acreditarmos que o discurso literário pode proporcionar a qualquer aluno percepções de outras realidades e ainda pode estimular a criatividade. É importante que as atividades a serem trabalhadas em sala de aula estejam relacionadas com a vivência dos alunos, sendo estes agentes ativos que podem e devem relacionar-se entre si, com o texto, com os professores, além de poderem contribuir com suas experiências pessoais (SILVA, 1998).

Foi selecionado o texto $A$ verdadeira bistória dos três porquinhos, do autor Jon Scieszka por acreditar que, nessa história, haveria muitas oportunidades para inserir, nas atividades do ensino da LP escrita, exercícios relacionados à grafia das palavras, expressões e outros gêneros textuais. Essas relações foram possíveis dentro da sala de aula, um espaço aberto para diálogo e troca de ideias sobre o que realmente acontecia na história. A escolha se deu, também, pelo fato de todos os alunos já conhecerem o clássico da literatura infantil Os três porquinhos e, a partir daí, terem uma referência sobre outra versão da história.

Esse material proposto, baseado na história dos três porquinhos, foi ilustrado por meio das imagens criadas por uma professora da rede municipal de Ensino de Belo Horizonte. A ideia de usar uma ilustração que não fosse do livro original, se deu por acreditar ser preciso reler e pensar em algumas estratégias de entendimento de partes específicas e expressões presentes na história que não estavam presentes na ilustração da edição disponível. Percebe-se grande importância da visão da ilustradora em relação às imagens, as quais possibilitaram marcações de detalhes imagéticos que iam ao encontro da história e ao sentido pretendido para cada trecho. Essas marcações são pistas visuais como a visita do lobo a cada casa e a xícara na mão do lobo, cerne da história: o lobo vai até a casa do porquinho pedir uma xícara de açúcar porque estava fazendo um bolo para sua 
amada vovozinha, conforme mostra a Figura 1, o que contrasta com a outra versão em que o lobo é mau e queria comer os porquinhos porque estava com fome.

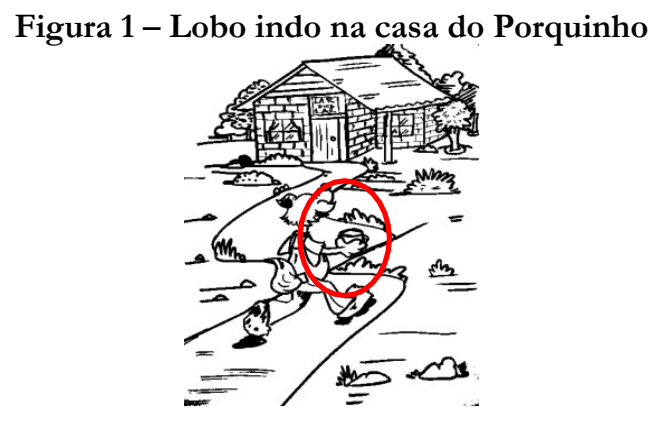

Fonte: Elaborado por Isabel Cristina Martins ${ }^{7}$

Outras marcações relevantes nas imagens criadas pela professora são a capa da história que remete a uma manchete de jornal, o espirro e o lenço no nariz, como demonstração de que o lobo estava gripado:

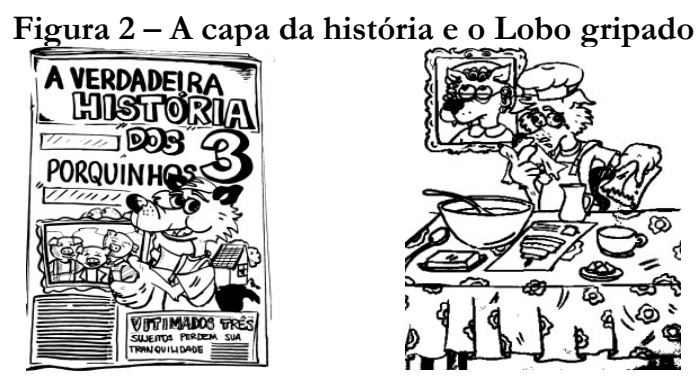

Fonte: Elaborado por Isabel Cristina Martins

O material de construção ficou evidente em relação às casas serem feitas de palha, lenha e tijolo:

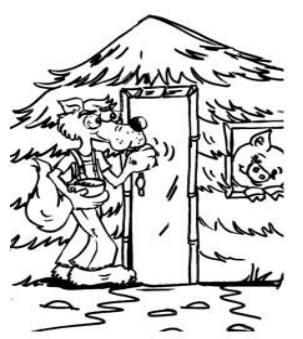

Figura 3 - Tipos de casa
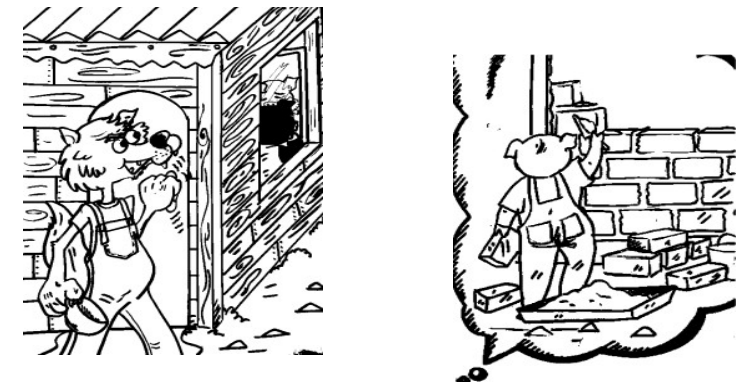

Fonte: Elaborado por Isabel Cristina Martins

A forma como o lobo aparece nas cenas, inflando e bufando para derrubar a casa, veio da intenção da pesquisadora de trazer veracidade e compreensão ao sentido das palavras em relação ao texto escrito, conforme Figura 4:

7 Professora da Rede Municipal de Ensino de Belo Horizonte. 
Figura 4-O lobo inflando e bufando

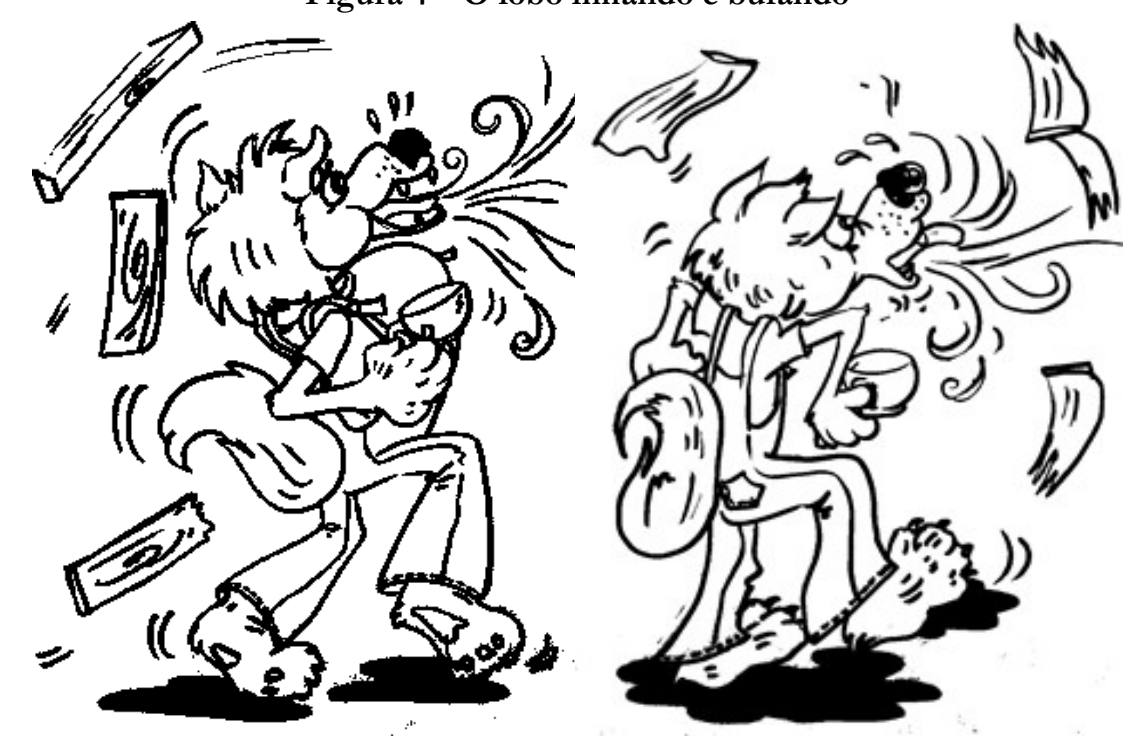

Fonte: Elaborado por Isabel Cristina Martins.

As imagens foram utilizadas em tamanho A4, para a contação da história e para colorir. O momento de contação da história e durante a execução das atividades, pretende-se uso simultâneo de Libras e de Língua Portuguesa escrita, atreladas sempre às imagens. Com todas as pistas visuais sobre o conteúdo da história, as imagens foram recortadas e inseridas nas atividades. Embora Oliveira (2006, apud LEBEDEFF, 2010), nos diga que as imagens ainda funcionam como enfeite do texto linear, a proposta foi ler a imagem como texto e considerar as pistas visuais do contexto de uma linguagem visual com a qual se pudesse interagir para construir significados.

O material didático foi proposto, então, com uso de imagens para o ensino da leitura e escrita do português destes alunos em fase de alfabetização, por entender que o canal de aprendizagem é o visual. Assim elas não foram meramente ilustrativas, foram usadas para promover a associação do significante (palavra ou expressão escrita) e do significado (conceito). Nesse material, o pressuposto é ensinar com a imagem o português escrito e Libras, três códigos diferentes presentes nos modos escrito, visual e sinais. Para além do ensino do português escrito, o material didático contribui também para o ensino de Libras, pois o uso da Língua de Sinais nos parece importante para a compreensão do texto escrito. Essa língua usada na implementação do material pode ter suporte nas imagens criadas também para as atividades de alfabetização.

Em todas as atividades, foram consideradas as ideias de Soares (2009) e Quadros (2005, 2006), as autoras trazem questões pertinentes ao ensino da leitura e da escrita da LP e sobre Libras como língua mediadora. Ambas defendem a não dissociação da alfabetização e do letramento, levando o aluno à vontade de escrever, respeitando sua escrita inicial. Com base no letramento e não apenas na codificação e decodificação, o texto literário permitiu a inserção de outros gêneros como a receita, produção textual e também leitura das imagens como a capa da história que remete ao gênero jornal.

A aplicação do material didático teve como objetivo investigar o uso dele no contexto de duas escolas, especial e regular, e verificar a percepção das docentes quanto ao ensino da leitura e escrita no português a partir da literatura infantil sob a noção de multimodalidade. Nos dois 
contextos tivemos situações diferentes, no contexto 1 sala de aula inclusiva com a presença de um profissional intérprete e no contexto 2, a professora referência usava a Libras para o ensino dos conteúdos e a presença de uma instrutora de Libras. Questionadas sobre o uso do material, as professoras apresentaram as seguintes avaliações apresentadas com base em Freitas (2018).

Ambas disseram não ter havido dificuldades na utilização do material didático frente às orientações que receberam da pesquisadora e autora, e afirmaram que usariam o material novamente em outras situações, reconhecem sua riqueza e sua adequação à situação. Entretanto, ambas disseram que seria interessante mais tempo para planejamento e execução, e que esse planejamento seria melhor se participassem dele com elaboração das atividades. As falhas que apontaram no material são de ordem organizacional e não pedagógica, como por exemplo, numeração das questões e das partes. Uma das docentes disse que uma dificuldade (não apontada pela outra professora) foi ter que sempre entregar folhas para os alunos, e isso a fazia ter que motivar os alunos sempre. A outra docente tinha alunos com diversos comprometimentos além da surdez naquela sala de aula, e isso a fez desacreditar do sucesso, mas reconhece que houve, pois conseguiu observar crescimento de interesse por parte das crianças.

Ao final constata-se que o material foi bem avaliado em termos pedagógicos nos dois contextos, abrindo espaços para novas pesquisas e reflexões quanto ao uso do material didático para alunos surdos. As professoras reconhecem que o material tem valor, riqueza e que pode promover resultados satisfatórios - o que nos permite dizer que a consideração da multimodalidade plenamente na elaboração e produção de materiais didáticos para surdos é algo defensável e pode trazer boa aceitação e eficácia na promoção de aprendizagem. O material está longe da perfeição plena, mas as professoras que o utilizaram reconhecem a necessidade de mais planejamento e se prontificam a usar novamente o mesmo material em situações diferentes. As professoras percebem o papel importante da orientação e consequentemente, isso mostra o papel formador de um material didático, pois a partir dele novos questionamentos e novas ideias surgem. A educação linguística de surdos ainda precisa de novas experiências a serem divulgadas, e do envolvimento não só de pesquisadores como dos professores envolvidos, em suma, requer formação contínua dos profissionais envolvidos.

\section{CONSIDERAÇões FINAIS}

Assumimos que o processo de aquisição da língua portuguesa escrita pelo aluno surdo é complexa e motivo de preocupação entre os educadores da área. Quadros (1997, 2006) enfatiza que a aquisição do português escrito por crianças surdas baseou-se no ensino do português para crianças ouvintes. As práticas de ensino de LP2 se orientaram por uma concepção de língua como código e recurso único para chegar à segunda língua; e assim resultou no ensino sistemático e padronizado de estruturas frasais da LP.

Quanto ao ensino de LP como segunda língua, defendemos que o professor vá além da simples tradução LS-LP-LS. Ele precisa ensinar ao aluno surdo a organizar as ideias, criar tópicos, discutir sobre o conteúdo e associar diferentes modos discursivos como a escrita, a imagem e a LS. Em outras palavras, é necessário estimular a escrita a partir das representações imagéticas e o uso de Libras, como no material didático aqui apresentado, de modo a se promover ensino de Libras a quem não a domina e de língua portuguesa para melhor inserção nas práticas de letramento. En- 
saios escritos, legendagem, notícias e reportagens, propagandas, histórias em quadrinhos, sinopses são exemplos de outros gêneros que podem promover uso dos modos escrito, sinais e imagens (estáticas ou em movimento). Também o texto literário, como aconteceu no material descrito, pode ser trabalhado, pois que se trata de uso significativo, funcional e real da língua, rico em estruturas e conceitos diversos, o qual pode ser juntadas a imagens criativas e adequadas para o ensino de português como L2 a surdos. É importante estabelecer, com o aluno surdo, momentos de linguagem escrita, explicar os diferentes modos de uso apoiando-se nos diferentes tipos de linguagem.

Assim, a elaboração de um MD para ensino de segunda língua, para crianças surdas, a imagem é um recurso fundamental. Está na interação entre escrita, sinais e imagem o estímulo à produção de sentido, de forma a se promover uma educação linguística de surdos que não apenas seja bilíngue (considerando Libras e português), mas que seja multimodal. Com isso, podemos afirmar que os modos escrita, imagem e sinais - todos visuais - são elementos naturais que auxiliam as crianças surdas (independentemente da diversidade auditiva) a alcançar maior sucesso na escrita em português como L2.

\section{REFERÊNCIAS}

ANN, J. Bilingualism and language contact. In: LUCAS, C. (Org.). The Sociolinguistics of Sign Languages. Cambridge: Cambridge University Press, 2004

CARVALHO, M. C. G. O papel do Inglês como primeira língua em ensino-aprendizagem de português, como segunda língua, para estrangeiros. Tese de doutorado. Programa de Pós-Graduação em Letras do Centro de Teologia e Ciências Humanas, PUC-Rio, 2013

FREITAS, L. A. G. A multimodalidade no ensino de leitura e escrita na Língua Portuguesa para alunos surdos nas séries iniciais do ensino fundamental: uma proposta de material didático. Dissertação de Mestrado, Programa de Estudos Pós-Graduação em Estudos de Linguagens do CEFET-MG, Belo Horizonte, 2018.

HEMAIS, B. J. W. Práticas pedagógicas no ensino de inglês: integrando gêneros discursivos e multimodalidade. In. HEMAIS, B. J. W. (Org.). Gêneros Discursivos e Multimodalidade: desafios, reflexões e propostas no ensino de inglês. Campinas: Pontes Editores, 2015, p. 19-32.

KRESS, G. Multimodality: a Social Semiotic approach to contemporary communication. USA e Canadá: Routledge, 2010.

LEBEDEFF, T. B. Aprendendo a ler "com os olhos": relatos de oficinas de letramento visual com professores surdos. Cadernos de Educação. FAE/PPGE/UFPel. Pelotas, maio/agosto, 2010, p. 175-195.

LEFFA, V. J. Como produzir materiais didáticos para o ensino de línguas. In. LEFFA, V. (Org.). Produção de materiais de ensino: teoria e prática. 2. ed., Pelotas. EDUCAT, 2007.

MAYBERRY, R. I. When timing is everything: Age of first-language acquisition effects on second-language learning. Applied Psycholinguistics, v. 28, n. 3, 2007, pp. 537-549.

QUADROS, R. M. Educação de surdos: a aquisição da linguagem. Porto Alegre: Artmed, 1997.

QUADROS, R. M. Educação de surdos: efeitos de modalidade e práticas pedagógicas. In: Mendes, E. G.; Almeida, M. A.; Williams, L. C. de A. (Org.). Temas em educação especial IV. São Carlos: EdUFSCar, 2004, p. 55-61.

QUADROS, R. M. O ‘bi’ em bilinguismo na educação dos surdos. Surdez e bilinguismo. 1 ed. Porto Alegre: Editora Mediação, v.1, 2005, p. 26-36.

QUADROS, R. M.; SCHMIEDT, M. L. P. Ideias para ensinar português para alunos surdos. Brasília: MEC/ Seesp, 2006

PLAZA-PUZT, C. Deaf education and bilingualism. In: PFAU, R.; STEINBACH, M.; WOLL, B. (Eds.). Sign Language: An International Handbook. Berlin, Germany: De Gruyter Mouton, 2012, p. 949-979. 
PEREIRA, M. C. C. O papel da língua de sinais na aquisição da escrita por estudantes surdos. Secretaria da Educação, CENP/CAPE-SP, 2009.

SÁNCHEZ, C. Os surdos, a alfabetização e a leitura: sugestões para a desmitificação do tema. Mimeo, 2002. SERAFINI, F. Expanding perspectives for comprehending visual images in multimodal texts. In: Journal of Adolescent \& Adult Literacy 54(5); International Reading Association. February, 2011, pp. 342-350.

SILVA, R. C. O uso do texto literário no livro didático de inglês elaborado a partir da abordagem comunicativa. Dissertação de Mestrado. Programa de Pós-Graduação em Estudos Linguísticos - Faculdade de Letras / UFMG, 1998, 106fl.

SILVA, R. C. Livro didático de inglês: que livro é este? Discursos de produtores e usuários. 1. ed., Curitiba: Appris, 2016.

SOARES, M. Letramento: um tema em três gêneros. 3. ed., Belo Horizonte: Autêntica, 2003.

SOARES, M. Letramento: um tema em três gêneros. Belo Horizonte: Autêntica, 2009.

SOARES, M. Letramento. In: Glossário Ceale - Termos de alfabetização, leitura e escrita para educadores. Belo Horizonte: CEALE/FAE/UFMG, 2015. Disponível em http://bit.ly/2QVMuiN. Acesso em 15/02/2018.

TAVIEIRA, C. e ROSADA, L. Por uma compreensão do letramento visual e seus suportes: articulando pesquisas sobre letramento, matrizes de linguagem e artefatos surdos In: Espaço, n.39, jan./jun. Rio de Janeiro, 2013, p. 27-42. 